\title{
Site Selection Criteria for Battery Energy Storage in Power Systems
}

\author{
Hameed, Zeenat; Hashemi Toghroljerdi, Seyedmostafa; Træholt, Chresten
}

Published in:

Proceedings of $33<$ sup $>$ rd $</$ sup $>$ Canadian Conference of Electrical and Computer Engineering

Link to article, DOI:

10.1109/CCECE47787.2020.9255678

Publication date:

2020

Document Version

Peer reviewed version

Link back to DTU Orbit

Citation (APA):

Hameed, Z., Hashemi Toghroljerdi, S.r\& Træholt, C. (2020). Site Selection Criteria for Battery Energy Storage in Power Systems. In Proceedings of $33^{\text {r }}$ Canadian Conference of Electrical and Computer Engineering IEEE. https://doi.org/10.1109/CCECE47787.2020.9255678

\section{General rights}

Copyright and moral rights for the publications made accessible in the public portal are retained by the authors and/or other copyright owners and it is a condition of accessing publications that users recognise and abide by the legal requirements associated with these rights.

- Users may download and print one copy of any publication from the public portal for the purpose of private study or research.

- You may not further distribute the material or use it for any profit-making activity or commercial gain

- You may freely distribute the URL identifying the publication in the public portal 


\title{
Site Selection Criteria for Battery Energy Storage in Power Systems
}

\author{
Zeenat Hameed ${ }^{1}$, Seyedmostafa Hashemi ${ }^{2}$, Chresten Træholt ${ }^{3}$ \\ Department of Electrical Engineering \\ Technical University Denmark \\ Kongens Lyngby, 2800, Denmark

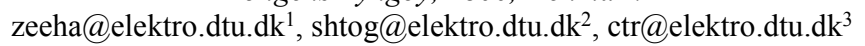

\begin{abstract}
Battery energy storage systems (BESSs) have gained potential recognition for the grid services they can offer to power systems. Choosing an appropriate BESS location plays a key role in maximizing benefits from those services. This paper aims at analyzing the significance of site selection for placement of BESS in a power grid by providing a techno-economic evaluation with respect to specific grid services it can deliver, and benefits that can be extracted from those services in the form of revenue streams. The focus of the previous studies extended in this direction has been limited to the optimization techniques and software tools being used for BESS siting. However, questions around the benefits that stakeholders can derive from BESSs located at different levels of power network still remain unanswered. This paper handles those questions by drawing a link between technical considerations essential for BESS placement and their economic evaluations.
\end{abstract}

Keywords - battery energy storage systems, battery placement, grid services, revenue streams, use cases, renewable energy sources integration, site selection

\section{INTRODUCTION}

In the modern society, electricity demand is increasing. Concerns regarding sustainability and environmental issues are also on rise, which are driving developments in power delivery systems. Emergence of smart grid technologies and advancements in transmission and distribution systems are few examples of these developments. It has been recognized that their potential growth depends on large scale deployment of utility scale battery energy storage systems (BESSs). This is because BESSs can provide multitude services to regional transmission and distribution systems, utilities and consumers [1]. Consequently, BESSs have gained extensive popularity which has led to their technical maturity and cost reduction [2]. As selecting a suitable site is among the first steps in the process of BESS installation, finding an optimal location with respect to what services BESS is meant to yield is a crucial task. It implies several careful considerations; interests of all stakeholders in the project must be considered, legal matters regarding grid connection must be met, technical criteria from manufacturers and suppliers must be fulfilled, and local plans and initiatives as well as different use cases to benefit the customers must be carefully evaluated.

This work is supported by the Danish project "BOSS: Bornholm smartgrid secured by grid connected battery systems" co-founded by Danish Energy technology Development and Demonstration program (EUDP) contract no. 64018-0618.
Even though abundant literature is found targeting multiple domains of BESS, such as, comparison of BESS with other energy storage systems (ESS) [3], [4] and classification of grid services BESS can provide [5], work specifically directed towards techno-economic evaluation of BESS siting problem is still scarce. The major focus of the review articles extended in this direction has been towards the optimization tools used in placement studies found in literature [6], [7]. Another study [8] evaluated BESS placement by classifying its services with respect to the major actors in energy market, focusing on optimization techniques not evaluating the benefits those actors were deriving from it.

This paper therefore aims to bridge the gap in BESS placement studies by reviewing work done in this area while drawing a link between technical considerations essential for BESS siting and economic benefits that can be gained from such considerations. Firstly, a technical analysis of site selection criteria for BESS is presented, with respect to specific grid services it can deliver when installed at specific levels of a power network. Then, economic criteria is discussed by proposing use cases, to analyze benefits of those grid services to different stakeholders in the form of revenue streams.

The structure of the paper is as follows. Section II highlights the grid services that utility scale BESS can provide and establishes their importance in power systems. In section III to provide those services, technical evaluation criteria for BESS siting is presented with respect to different levels of power network i.e. transmission network level, distribution network level and BESS co-located with variable renewable energy (VRE) generators. In section IV, an economic evaluation criteria for BESS siting is presented to understand monetization of value obtained from grid services. Section V evaluates the impact of establishing techno-economic evaluation criteria on BESS placement studies. Finally, section VI concludes the paper with a brief summary and concluding remarks.

\section{GRID SERVICES FROM BESS}

BESS placement studies are of paramount importance as geographical flexibility is a feature unique to BESS, as opposed to most of the other ESS. For example, conventional ESS like pump hydro, require special geological conditions, like mountains, water, etc. to be functional. Utility scale BESS on the other hand can be deployed closer to where the additional flexibility is needed and can provide services required at the point of installation. For example, for system operators, BESS can provide frequency response services and regulation 
reserves. They can also defer investments in peak generation and grid reinforcements. They also enable greater penetration of VRE into the grid by storing excess generation and by firming the renewable energy output. Even though BESS can provide multiple services, certain technical constraints limit their deployment at certain locations of power network. Similarly, the value propositions of those services are also a deciding factor that whether or not those services should be targeted. To better comprehend these ideas, firstly, an understanding of potential available grid services should be developed. Only then technical feasibilities and placement criteria of those grid services in a power grid can be analyzed, and a reality check on profitable deployment of those services at proposed locations can be established.

The most important grid services that BESS can provide for power systems are classified in the Fig. 1 and discussed in remainder of this section.

\section{A. Frequency Regulation}

Primary, secondary and tertiary frequency regulations are the three kinds of frequency regulation. In primary frequency regulation, synchronous generators produce instantaneous power to balance supply and demand of power within tens of seconds. Centralized control center usually plays a role in secondary frequency regulation by driving the system frequency back to the nominal value. Tertiary frequency regulation often serves as an economic power dispatch center aimed at economically adjusting the outputs of the generators. However, the task of frequency regulation becomes challenging because of the intermittence of RES. To address this challenge, BESS can provide promising solutions. This is because, in contrast to BESSs, the capacity and the number of automated generation control (AGC) units used by synchronous generators are limited. Therefore, BESS can provide higher power response and quick frequency regulation services [9], [10]. When a need for frequency regulation arises because of a dip or rise in grid frequency caused because of an imbalance between power supply and demand, BESS is charged or discharged within milliseconds in response to an increase or decrease of this grid frequency and keeps it within pre-set limits [11], [12].

\section{B. Flexible Ramping}

Flexible ramping is another important grid service provided by BESS. It helps in maintaining a balance in power system operations by adjusting its power output to match the requirements of time-varying load [13]. Time varying load amounts to the uncertainty that exists in electricity markets, by referring to the difference between renewable generation and system load [14]. BESS reduces this uncertainty that in turn helps in achieving another service called capacity firming, which is discussed later in this section.

\section{Black Start and Capacity Reserve}

BESS can also provide black start services, which are required in an extreme situation of complete grid failure. High restoration power is required to bring the generation plants back into play. This is traditionally done by diesel generators. As the need for black start is a rare event, BESS can continue to provide other services when black start is not required and generate revenue. Consequently, BESS does not remain idle. This is not

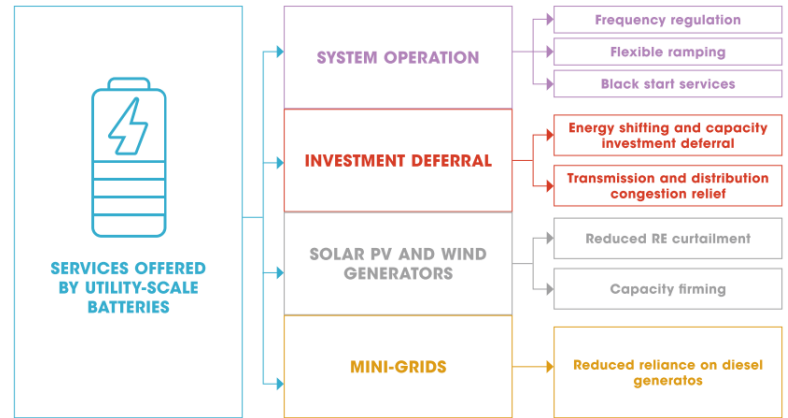

Fig. 1: An overview of grid services provided by BESS [11]

the case with high power diesel generators, which are installed with a high capacity that is rarely used but sits idle rest of the times [15], [16]. Large-scale BESS are also well suited to serve as capacity reserves as they can discharge during peak hours, displacing peak-generators and deferring further investment in peaking plants [11].

\section{Transmission and Distribution Congestion Relief}

Another important service that BESS can provide is transmission and distribution (T\&D) congestion relief. As the power demand fluctuates greatly all year round, the peak demand can actually surpass the load carrying capacity of T\&D network and result in network congestion. To cater to this problem, upgrades in these networks are essential. This is a costly solution, especially because those upgrades are required only during periods of network congestion, which are rare. BESS address this issue by storing energy from renewable sources and releasing it in period of peak demand [11].

\section{E. Renewable Integration Support and Capacity Firming}

BESS are also useful in increasing the volume of renewable power that can be safely and securely connected to the grid. By incorporating BESS into the system, more renewable integration can be made under existing network capacity as surplus power can be stored in BESS. This helps in preventing renewable energy curtailment. If intermittent generation from renewable sources produces large amount of energy at times when demand is low, it can be stored for later use. Another service available from BESS that plays a role in increasing RES integration is capacity firming. This happens when BESS helps in smoothening the output of renewable sources, for example, by solving overvoltage's issue via voltage regulation [17]. Power fluctuations can also be regulated, which reduces uncertainty of supply, increases compliance with generation schedules and allows renewable energy source (RES) to make better auctions in energy and capacity market.

It is important to mention here that although BESS is capable of providing all of the above mentioned services, their value propositions greatly differ from one another. Regardless, attractive revenue generation potentials have been attributed to certain services. This includes ancillary services such as spinning reserves and frequency regulation. Other than these services, demand charge mitigation and demand response also show valuable revenue potential [18]. Therefore this paper puts a greater focus towards those specific services and evaluates them in greater detail. 


\section{Site Selection CRITERIA FOR Providing GRID SERVICES - TECHNICAL CONSIDERATIONS}

After developing a thorough insight on grid applications of BESS in the previous section, this section targets on establishing a site selection criteria for BESS in a power network, so that the full potential of those grid services could be harnessed. Certain applications are better targeted when BESS is deployed at certain voltage levels of the power grid. Frequency regulation, for example is a regulatory service application that usually occurs at transmission system level, but can occur at distribution level as well. Similarly, load levelling and peak shaving are generally targeted at the distribution system level.

Therefore, site selection criteria places BESS at one of the following locations, which are described in details in subsequent paragraphs:

- BESS in transmission network

- BESS in distribution network

- $\quad$ BESS co-located with VRE generators

\section{A. BESS in Transmission Network}

BESS installed in transmission network is particularly useful in providing ancillary services. It can also store excess energy, thus deferring investments in system upgrade. By acting as an energy reserve, it balances the difference between generation and supply. Several sensitivity analysis techniques are used to predict and validate the feasibility of siting BESS at the transmission side of the grid to regulate grid frequency and cope with contingencies, if need arises [19].

Primary frequency regulation (PFR) has so far been one of the greatest value application driven from BESS, which occurs at transmission level. Traditionally, synchronous generators have provided this service. In the absence of BESS, a part of generator capacity performing PFR has to be reserved for this service. On top of that, the process occurs with a slow response speed [20]. As BESS has a high power capacity and lower discharge rate, it can provide a fast response and hence a better frequency imbalance handling capability [20]. When BESS is used for PFR, it is recommended to interpret BESS location according to the most severe contingency for generation outage. Considering different penetration levels of RES integration is also essential for the proper deployment of BESS at transmission network level [21].

\section{B. BESS in Distribution Network}

All the services provided in the transmission networks can also be provided by installing BESS in distribution networks. In addition to that, power quality and congestion services are more specific to distribution network level. BESS can be deployed near the load centers to provide peaking capacity due to the scalability they can provide. Conventional generators usually do not provide this flexibility as they raise concerns about land use and toxic emissions [20].

BESS placement at distribution level depends on factors such as charge-discharge cycles, stakeholders involved and amount of RES installation planned. Once an optimal location is determined, power absorbed and delivered by BESS needs to be regulated [22]. It is also crucial to develop location algorithms to identify what point of RES integration has the greatest effect on overvoltage, so they can be regulated by BESS [23], [24]. In a power system, voltage levels are disturbed if a fault occurs; therefore, in BESS placement studies for distribution system, it is essential to consider fault and contingency analysis. Location of BESS to prevent cascaded tripping following a fault should be also evaluated and voltage profile and recovery time should be calculated to ensure voltage stability [25], [26].

\section{BESS Co-Located with VRE Generators}

RES plants are not always located close to the load centers, as their location is dependent on availability of adequate supply of natural resources such as wind or solar. Therefore, to deliver power where it is needed, transmission investments are needed, which might go underutilized for large periods of time, owing to the variability in availability of RES. The storage capacity of BESS plays a role in deferring investment, by storing charge during periods of high RES availability and discharging the stored energy when availability decreases.

When optimal locations of distributed generators (DGs) and BESSs are determined, it is essential to evaluate the requirements for each season over the whole year as it gives a holistic idea of renewable energy availability patterns [27], [28]. It is also essential to evaluate multiple network conditions, such as fixed or variable operation pattern and location for both DG and BESS. By considering such conditions, best possible locations for BESS can be predicted, which might not necessarily come out to be the same for different network conditions. For example, a network under heavy loading might propose BESS installation at location quite different from when the same network is considered under light loading. Thus, placing BESS far from RES is one way towards appropriate site selection, on the other hand, BESS co-located with VRE generators can also be deployed by considering battery coupled photovoltaic generators in distributed networks. In this case, it becomes essential to determine location of the whole coupled systems under specific constraints such as minimizing cost and losses [29].

It can be concluded that certain technical considerations should be kept in mind while choosing an appropriate location for BESS. Depending on what level of power network BESS in being placed and what grid services are being targeted a that level, these considerations might vary. BESS placement should therefore be evaluated on case to case basis.

\section{Site Selection CRiteria For Providing GRID SERVICES - ECONOMIC CONSIDERATIONS}

Previous section, presented a technical analysis of grid services that BESS can provide at various locations. For better project handling, economic evaluation of BESS services is also required [30], [31]. This economic evaluation can be done in two ways; cost evaluation or revenue stream evaluation. A Despite the abundance of literature available, studies are mostly directed towards former, while the latter is rarely investigated. So, in most cases, BESS installation does not seem to provide promising margins to operate economically [30], [32]. Therefore, it is essential to specify and analyze various use cases to evaluate if BESS services could yield a profitable investment, and then determine the revenue streams with respect to those specified use cases [33]-[36]. 


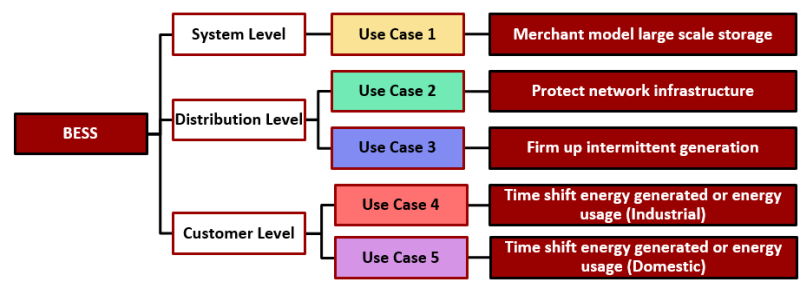

Fig. 2: Flowchart of use cases for different BESS placement locations

\section{A. Significance of Defining Use Cases in Economic Evaluations}

Use Cases of BESS contain information for answering to the larger questions surrounding the true value of BESS, such as the overall value that BESS can provide to the grid. They select those few, precisely targeted services which are economically viable and technically beneficial. They explain how exactly the value of BESS is defined; and how to monetize the value in a way that benefits stakeholders and drives adoption [37]. Each use case tells how BESS can meet the identified needs, the drivers for installing the BESS e.g. increasing energy security, sustainability, etc. [38] and potential monetary benefits of BESS services accrued to whoever is paying for them.

In an electricity value chain, these potential monetary benefits could either be in the form of the revenues received by the BESS owners or operators or they can be in the form of cost avoidance or reduction by BESS. Generally, energy markets and bilateral contracts, help to realize the revenues generated. On the other hand cost reduction is harder to infer. Hence, further signifying the fact that use cases should be analyzed in greater depth. This is done in the following paragraphs in three steps

- Firstly, five use cases are identified with respect to three installation locations of BESS, namely transmission system level storage, distribution level storage or customer level storage. This implies that if BESS is installed at the specified location, certain use cases can be described for it. This is illustrated in Fig. 2, out of five use cases, one use case falls under the transmission system level storage category, two use cases under the distribution system level storage and two under customer level storage. Details on what each use case implies is also given in the Fig. 2.

- Secondly, the use cases are considered for both scenarios of RES integration i.e. with and without intermittent generation. This is done to signify that the systems with intermittent generation need to be evaluated differently for their revenue potential than those without it. For example, analyzing the weather data to develop energy forecast models for VRE generators is important for their economic evaluations, which is not the case for conventional generation plants. This is illustrated in Fig. 3 by placing a green box within the use case block which represents presence of intermittent generation. For example, for use case 3, for the system (blue) RES integration is not considered, hence only red box representing BESS installation is depicted. On the other hand, use case 4 (represented by orange box)

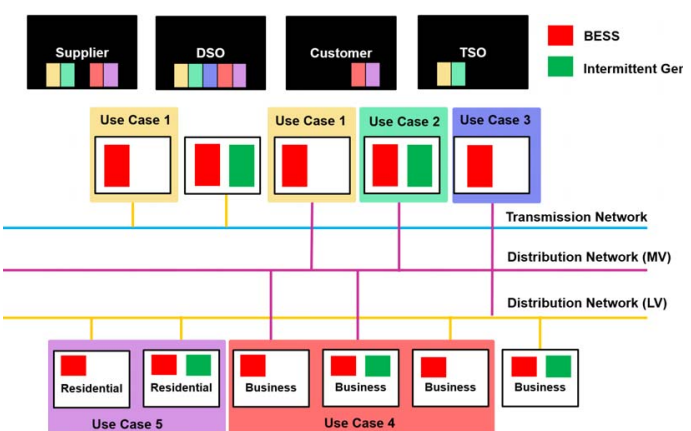

Fig. 3: Use cases of BESS at transmission and distribution network and their potential stakeholders in the energy market

encompasses both BESS as well as RES integration, thus represented by placing red and green boxes within the system.

- Lastly, the use cases are also analyzed with respect to their respective beneficiaries such as supplier, distribution system operator (DSO), customer or transmission system operator (TSO) [39]. This is presented in Fig. 3, by incorporating beneficiaries of each use case in color coded boxes within the black blocks on the top. It can be seen that the benefits of use case 1 are accrued to all beneficiaries represented except for the customers, therefore, a yellow box is placed in all black blocks representing beneficiaries; supplier, DSO and TSO. On the other hand, value from use case 4 is accrued by all beneficiaries considered; hence an orange box is placed in all four black blocks.

The following paragraphs, present a brief description of all five use cases, identified within three different BESS placement locations, to better understand their roles in a power network.

\section{B. Transmission System Level}

The use cases under this category consider situations when BESS is connected to transmission network and is primarily being used for balancing the power system and is providing ancillary services at the regional level. One use case is considered here

- Use case 1: A BESS model that sells goods or services, is called a merchant model. There are a number of market services offered by regional grid, in which BESS can participate, while ensuring it meets the specifications set by the service requirements. In this use case, BESS owner has full control over its ownership and operation, and is responsible for monetizing its value. As the owner finances the system, he has an access to the revenue streams from supplying services to the market [40]. If the owner is TSO, financial benefits are from response services such as constraint management, or from enhanced frequency response. While this use case is focused towards transmission system level, suppliers can also give access to other parties wanting to participate in regional grid services. When this happens, this merchant model can be extended to represent a use case at distribution system level as well. If the owner is DSO, financial benefits are accrued from demand side 


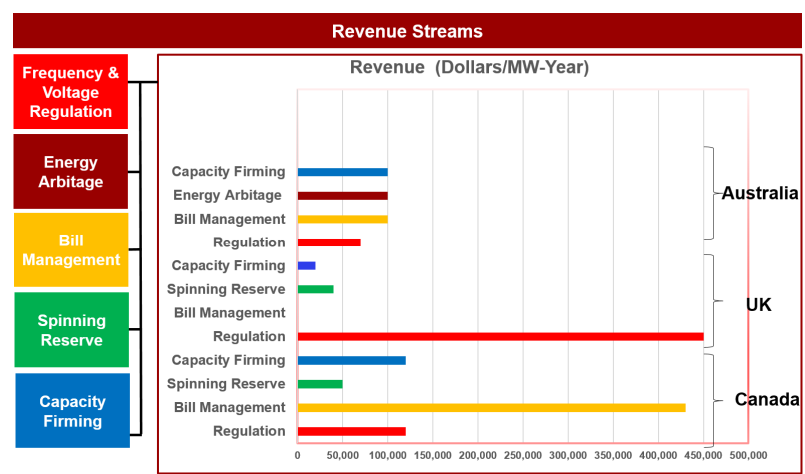

Fig. 4: Revenue streams from different grid services from BESS among different countries, from the data available in [18].

response. Similarly, if the owner is the supplier, financial benefits are accrued from ancillary services, as long as the supplier surpasses competitors in quality and quantity of those services.

\section{Distribution System Level}

The use cases under this category consider situations when BESS is connected to medium voltage distribution network to defer reinforcements, or it is deployed by intermittent generators to overcome the stability. Two use cases are considered here

- Use case 2: It is essential to keep the distribution network running within its operating constraints even when the demand and generation on the network increases with time. For this, reinforcement of distribution network is importance and is the responsibility of the DSO. Previously, this was done by increasing capacity or reconfiguring connections, which was a slow and disruptive process. The upheaval that might be caused in the network infrastructure would worsen, as we go lower down the system hierarchy in a power network. There is also a cost associated with replacements in service cables, pants and substations. To resolve this, BESS can provide a quicker, and potentially lower cost solution to conventional reinforcement. Even though this use case is not generating a direct revenue, the DSO still derives financial benefits from this setup. Simply because of the fact that the budget that would have been spent on the network upgrade is now saved or used elsewhere [41] [42]. Similar case can be made for transmission network, where TSO would be the major beneficiary.

- Use case 3: Typical intermittent generation connected to the distribution network has a non-firm agreement due to the high cost of a firm agreement. A non-firm agreement means that the DSOs can restrict export from intermittent sources when the network has an excess of supply available which restricts the revenue gained. As BESS can absorb power from the renewable assets, its installation implies that a lower cost non-firm agreement can be made which reduces the agreement cost and ensures that the output from renewable plants is not wasted. Secondary benefit such as ability to sell energy in blocks back to the market is also significant. The suppliers and DSO benefit from the revenue generated from this use case [43].

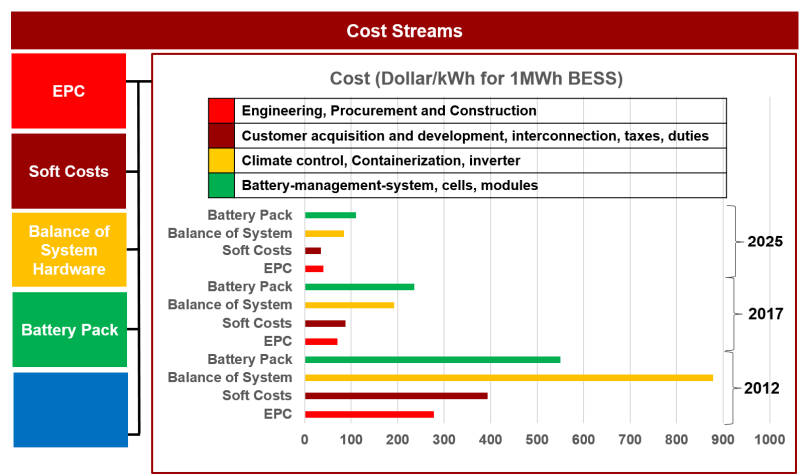

Fig. 5: Cost Streams for different services for BESS. Past cost streams and their estimated future projections from the data available in [44]

\section{Customer Level}

The use cases under this category consider BESS connected to low voltage distribution network for domestic, industrial or commercial use. Two use cases are considered here

- Use case 4: Energy arbitrage through BESS offers a significant potential to businesses to reduce power costs. This happens, when there is an excess of energy onsite, and is stored by BESS, so it can be used when demand arises. It also enables the customers to abstain from paying high electricity costs during peak load hours. If the energy is stored and used at a point when demand is high, then the energy requested from the grid and a customer's bill is reduced. Also, if supply contracts align with periods of high network stress then peak shaving helps to defer network investment which directly benefits the DSOs. Hence, the suppliers, DSO and customer benefit from the revenue generated from this use case [45], [46].

- Use Case 5: At a household level, renewable energy can be stored in BESS and used when required, with a motive to reduce electricity bill. Hence customers financially benefit from this use case. But not just that, in case when BESS is controlled by DSO, generation and demand can be reduced or restricted in a way that revenue streams are maximized.

\section{E. Other Essential Parameters in Economic Evaluations}

It is important to note that in market settings, technical and regulatory parameters along with economic parameters govern the potential of individual use cases. This potential can be better encapsulated by business models, as they also seek value for money for the consumers along with economic value for stakeholders [47]. Therefore, identifying target customers and what they seek, is another aspect in BESS economic evaluations [48], [49]. Also, as BESS applications have different value potentials with respect to benefits and applicability, placement studies should target applications with high value potential, to be better suited for utility scale applications [50]. As within an electricity market, net value of grid services is not the same, therefore the value propositions of grid services and energy storage might differ depending on the case studies at hand [51]. This is highlighted in Fig. 4, where the revenue generated in different regions of the world such as Canada, UK and Australia are compared. It can be seen that the value obtained from a 
specific service for example frequency and voltage regulation, differs amongst these countries. Fig. 5, further highlights various costs streams of BESSs and presents a comparison of future projected estimates with the past years. It can be derived that expected reduction in costs would promote higher usage and greater revenues in the future electricity market.

\section{IMPACT OF TECHNO-ECONOMIC EVALUATIONS ON BESS PLACEMENT STUDIES}

From the former sections it has become evident that whenever a grid service is considered for BESS, it becomes crucial to investigate whether or not it would be technically feasible to target specific grid services and if it would have profitable revenue streams or not. It is important to note that, even though high revenue streams can be targeted from some of the grid services, there are still high costs associated with BESS that cannot be ignored in economic evaluations[52].

High investment costs contribute the most to high costs of BESS. It has been seen that declining costs of any technology plays a crucial role in boosting its usage. For example, the share of Li-ion batteries have increased tremendously over the last few years, which is mostly driven by declining costs of such batteries, that in turn can be traced to increasing demands for electric vehicles [11]. Despite this boom in Li-ion technologies, a lot of work still has to be done until BESS can provide services that are at par with conventional equipment in transmission and distribution networks. A fortunate solution to the obstacle of high costs associated with BESS lies in the fact that BESS can be used for multiple applications at a time. So, even at a high initial cost, by targeting all the desired applications together, a strong case for BESS utilization can be made. This process of extracting multiple synergic applications of BESS will be cost effective. It will not only help to expand the arenas of derived benefits, but also justify high investments costs.

To ensure that this process runs smoothly, designing optimal investment plans beforehand is essential. For this multiple investment scenarios and several dispatch schedules need to be considered [52], [53]. Once investment plans are finalized and operational profiles are selected, aggregation potential of stacked revenue streams can be evaluated. If they present a comparable potential with capital and operational costs over their lifetime and if the proposed investment plans for selected stacked services confirm viability, the next step would be finding an optimal location for BESS placement. Site selection for multipurpose BESS application would be more challenging than single application scenarios that have been discussed in this paper, as essential tradeoffs would be required. Therefore, site selection task is crucial as placing BESS at a non-optimal location might demand a BESS with a larger capacity to be installed, which may lead to higher initial costs, which were meant to be avoided at the first place. System losses might also increase which is not desirable in power systems [54].

Finally, as the selection for a utility-scale BESS is a holistic process, and since no two projects are the same, the process might begin with a different focus for different installations [55]. There are, of course, some common elements of utility-scale BESS and the public electricity supply grid voltage levels; however, a potential decision-making approach for site selection can be designed only through proper consideration of grid- applications for BESS as well as rules and regulations that affect the site selection, safety and local considerations, such as district plans or environmental concerns.

\section{CONCLUSIONS}

This paper provided a detailed analysis of potential grid services that BESS can provide and defined certain use cases to establish how those services can be deployed by BESSs. It also established the importance of evaluating use cases with respect to their collective revenue streams, highlighting benefits accrued to the involved stakeholders. This study therefore, signifies the fact that whenever technical considerations are made for BESS installation, economic evaluations are equally important to gain a holistic insight, only then appropriate deployment of BESS at most desirable location can be achieved. It was concluded that by deploying BESS at distribution system level, best mix of technically feasible grid applications can be achieved. This point is further strengthen by considering that when economic evaluation was conducted, only for DSOs the financial benefits were accrued from all of the five selected use cases. This implies that the most revenue streams can be obtained at this level, further supporting the case for installation of BESS at distribution system level

\section{REFERENCES}

[1] National Rural Electric Cooperative Association, "Business \& Technology Report Battery Energy Storage Overview," 2019.

[2] T.-T. Nguyen, V. Martin, A. Malmquist, and C. A. S. Silva, "A review on technology maturity of small scale energy storage technologies," Renew. Energy Environ. Sustain., vol. 2, p. 36, 2017.

[3] D. Connolly, "A Review of Energy Storage Technologies," 2010.

[4] A. Saez-De-Ibarra et al., "Analysis and comparison of battery energy storage technologies for grid applications," in 2013 IEEE Grenoble Conference PowerTech, POWERTECH 2013, 2013.

[5] H. C. Hesse, M. Schimpe, D. Kucevic, and A. Jossen, Lithium-ion battery storage for the grid - A review of stationary battery storage system design tailored for applications in modern power grids, vol. 10, no. 12. 2017.

[6] S. Salee and P. Wirasanti, "Optimal siting and sizing of battery energy storage systems for grid-supporting in electrical distribution network," in 1st International ECTI Northern Section Conference on Electrical, Electronics, Computer and Telecommunications Engineering, ECTINCON 2018, 2018, pp. 100-105.

[7] M. Zidar, P. S. Georgilakis, N. D. Hatziargyriou, T. Capuder, and D. Škrlec, "Review of energy storage allocation in power distribution networks: Applications, methods and future research," IET Gener. Transm. Distrib., vol. 10, no. 3, pp. 645-652, Feb. 2016.

[8] J. L. Lorente, X. A. Liu, R. Best, and D. J. Morrow, "Energy storage allocation in power networks - A state-of-the-art review," in Proceedings - 2018 53rd International Universities Power Engineering Conference, UPEC 2018, 2018.

[9] F. Arrigo, E. Bompard, M. Merlo, and F. Milano, "Assessment of primary frequency control through battery energy storage systems," Int. J. Electr. Power Energy Syst., vol. 115, no. August 2019, p. 105428, 2020.

[10] B. Khaki, P. Das, and S. Member, "Sizing and Placement of Battery Energy Storage Systems and Wind Turbines by Minimizing Costs and System Losses," arXiv Prepr. arXiv1903.12029, 2019.

[11] T. International Renewable Energy Agency, UTILITY-SCALE BATTERIES INNOVATION LANDSCAPE BRIEF. 2019.

[12] I. S. Jha, S. Sen, M. Tiwari, and M. K. Singh, "Control strategy for Frequency Regulation using Battery Energy Storage with optimal utilization," in India International Conference on Power Electronics, IICPE, 2015, vol. 2015-May.

[13] A. Hilbert, "Enhancing power system flexibility," Electronic Product Design, vol. 25, no. 11. pp. 37-41, 2004. 
[14] K. Westendorf, "California Independent System Operator Corporation California ISO Flexible Ramping Product Uncertainty Calculation and Implementation Issues," 2018.

[15] T. Bowen, I. Chernyakhovskiy, and P. Denholm, "Grid-Scale Battery Storage: Frequently Asked Questions."

[16] IRENA, "Utility-Scale Batteries," 2019.

[17] B. Gudimetla, S. Teleke, and J. Castaneda, "Application of energy storage and STATCOM for grid quality issues," in IEEE Power and Energy Society General Meeting, 2011.

[18] Lazard, "Lazard's levelized cost of energy analysis - version 12.0," Lazard, no. 12, pp. 0-19, 2018.

[19] M. Motalleb, E. Reihani, and R. Ghorbani, "Optimal placement and sizing of the storage supporting transmission and distribution networks," Renew. Energy, vol. 94, pp. 651-659, Aug. 2016.

[20] D. Mejía-Giraldo, G. Velásquez-Gomez, N. Muñoz-Galeano, J. B. CanoQuintero, and S. Lemos-Cano, "A BESS sizing strategy for primary frequency regulation support of solar photovoltaic plants," Energies, vol. 12, no. 2, pp. 1-16, 2019.

[21] M. Ramírez, R. Castellanos, G. Calderón, and O. Malik, "Placement and sizing of battery energy storage for primary frequency control in an isolated section of the Mexican power system," Electr. Power Syst. Res., vol. 160, pp. 142-150, Jul. 2018.

[22] S. B. Karanki and D. Xu, "Optimal capacity and placement of battery energy storage systems for integrating renewable energy sources in distribution system," in 2016 National Power Systems Conference, NPSC 2016, 2017.

[23] A. F. Crossland, D. Jones, N. S. Wade, and S. L. Walker, "Comparison of the location and rating of energy storage for renewables integration in residential low voltage networks with overvoltage constraints," Energies, vol. 11, no. 8, 2018.

[24] Y. Zhu, "Optimal battery energy storage placement for transient voltage stability enhancement [arXiv]," Arxiv, 2019.

[25] T. Aziz, N. Al Masood, S. R. Deeba, W. Tushar, and C. Yuen, "A methodology to prevent cascading contingencies using BESS in a renewable integrated microgrid," Int. J. Electr. Power Energy Syst., vol. 110, pp. 737-746, Sep. 2019.

[26] T. Chaiyatham and I. Ngamroo, "Bee colony optimization of battery capacity and placement for mitigation of voltage rise by PV in radial distribution network," 10th Int. Power Energy Conf. IPEC 2012, pp. 13$18,2012$.

[27] R. Hemmati, "Mobile model for distributed generations and battery energy storage systems in radial grids," J. Renew. Sustain. Energy, vol. 11, no. 2, Mar. 2019

[28] J. Gonçalves, L. Neves, and A. G. Martins, "Multiobjective methodology for assessing the location of distributed electric energy storage," in Lecture Notes in Computer Science (including subseries Lecture Notes in Artificial Intelligence and Lecture Notes in Bioinformatics), 2015, vol. 9028, pp. 227-238.

[29] A. Ali, N. Mohd Nor, T. Ibrahim, and M. Fakhizan Romlie, "Sizing and placement of battery-coupled distributed photovoltaic generations," $J$. Renew. Sustain. Energy, vol. 9, no. 5, Sep. 2017.

[30] G. Fong, R. Moreira, and G. Strbac, "Economic analysis of energy storage business models," in 2017 IEEE Manchester PowerTech, Powertech 2017, 2017.

[31] "Battery Energy storage systems (BESS): ancillary services and beyond," 2018.

[32] M. Klausen, M. Resch, and J. Bühler, "Analyis of a Potential Single and Combined Business Model for Stationary Battery Storage Systems," in Energy Procedia, 2016, vol. 99, pp. 321-331.

[33] P. Kassing, A. Sumper, T. Müller, and M. Heißwolf, "Battery storage systems feasibility study for revenue models in Germany," in Proceedings - 2017 International Conference on Modern Power Systems, MPS 2017, 2017.

[34] M. B. C. Salles, J. Huang, M. J. Aziz, and W. W. Hogan, "Potential arbitrage revenue of energy storage systems in PJM," Energies, vol. 10, no. 8, Aug. 2017.
[35] S. Vejdan and S. Grijalva, "Analysis of multiple revenue streams for privately-owned energy storage systems," in 2018 IEEE Power and Energy Conference at Illinois, PECI 2018, 2018, vol. 2018-January, pp. $1-5$.

[36] F. Braeuer, J. Rominger, R. McKenna, and W. Fichtner, "Battery storage systems: An economic model-based analysis of parallel revenue streams and general implications for industry," Appl. Energy, vol. 239, pp. 14241440, Apr. 2019.

[37] Acore, "Beyond Renewable Integration: The Energy Storage Value Proposition Beyond Renewable Integration: The Energy Storage Value Proposition AMERICAN COUNCIL ON RENEWABLE ENERGY," 2016

[38] D. Gl, "Energy Storage Use Cases DNV GL for BEIS," 2016.

[39] "The energy market explained | Energy UK." [Online]. Available: https://www.energy-uk.org.uk/energy-industry/the-energy-market.html. [Accessed: 14-Jan-2020].

[40] B. Zakeri and S. Syri, "Value of energy storage in the Nordic Power market - Benefits from price arbitrage and ancillary services," in International Conference on the European Energy Market, EEM, 2016, vol. 2016-July.

[41] L. Garcia-Garcia, E. A. Paaso, and M. Avendano-Mora, "Assessment of battery energy storage for distribution capacity upgrade deferral," in 2017 IEEE Power and Energy Society Innovative Smart Grid Technologies Conference, ISGT 2017, 2017.

[42] “Energy Storage Roadmap Report,” 2017.

[43] F. Braeuer, J. Rominger, R. McKenna, and W. Fichtner, "Battery storage systems: An economic model-based analysis of parallel revenue streams and general implications for industry," Appl. Energy, pp. 1424-1440, Apr. 2019.

[44] M. Fisher, J. Whitacre, and J. Apt, "A Simple Metric for Predicting Revenue from Electric Peak-Shaving and Optimal Battery Sizing," Energy Technol., vol. 6, no. 4, pp. 649-657, Apr. 2018.

[45] E. Storage, F. O. R. Future, and E. U. Role, "Energy storage for future energy systems and eu role and initiatives," vol. 2, no. 2, pp. 1-29, 2019.

[46] L. Boscán and R. Poudineh, "Business Models for Power System Flexibility: New Actors, New Roles, New Rules," in Future of Utilities Utilities of the Future: How Technological Innovations in Distributed Energy Resources Will Reshape the Electric Power Sector, Elsevier Inc., 2016, pp. 363-382.

[47] A. Burlinson and M. Giulietti, "Non-traditional business models for cityscale energy storage: evidence from UK case studies," Econ. e Polit. Ind., vol. 45, no. 2, pp. 215-242, 2018.

[48] "Supercharged: Challenges and opportunities in global battery storage markets Brochure / report title goes here | Section title goes here."

[49] "Beyond Renewable Integration: The Energy Storage Value Proposition Beyond Renewable Integration: The Energy Storage Value Proposition AMERICAN COUNCIL ON RENEWABLE ENERGY,” 2016.

[50] R. C. K Y Mou N, G. Fitzgerald, J. Mandel, J. Morris, and H. Touati, "The Economics Of Battery Energy Storage How Multi-Use, CustomerSited Batteries Deliver The Most Services And Value To Customers And The Grid The Economics Of Battery Energy Storage | 2"

[51] H. Saboori, R. Hemmati, S. M. S. Ghiasi, and S. Dehghan, "Energy storage planning in electric power distribution networks - A state-of-theart review," Renew. Sustain. Energy Rev., vol. 79, no. December, pp. 1108-1121, 2017.

[52] D. Khastieva, I. Dimoulkas, and M. Amelin, "Optimal investment planning of bulk energy storage systems," Sustain., vol. 10, no. 3, pp. 123, 2018.

[53] S. B. Karanki, D. Xu, B. Venkatesh, and B. N. Singh, "Optimal location of battery energy storage systems in power distribution network for integrating renewable energy sources," in 2013 IEEE Energy Conversion Congress and Exposition, ECCE 2013, 2013, pp. 4553-4558.

[54] C. Boss, B. Smartgrid, and K. Brunak, "Site Selection Criteria for UtilityScale Battery Integration,” 2019. 